\title{
AVALIAÇÃO DA PERCEPÇÃO DE DISCENTES DE MEDICINA SOBRE A GENÉTICA MÉDICA DURANTE O CURSO E A VIDA PROFISSIONAL, EM UM CENTRO UNIVERSITÁRIO DE BELÉM, PARÁ, AMAZÔNIA
}

\section{ARTIGO ORIGINAL}

MARTINS, Carlos Henrique Lopes ${ }^{1}$, LIMA, Gabriela Elenor dos Santos², DENDASCK, Carla Viana ${ }^{3}$, OLIVEIRA, Ciane Martins $\mathrm{de}^{4}$, OLIVEIRA, Euzébio de ${ }^{5}$

LOPES, Carlos Henrique Martins. Et al. Avaliação da percepção de discentes de medicina sobre a genética médica durante o curso e a vida profissional, em um Centro Universitário De Belém, Pará, Amazônia. Revista Científica Multidisciplinar Núcleo do Conhecimento. Ano 06, Ed. 03, Vol. 11, pp. 63-77. Março de 2021. ISSN: 2448-0959, Link de acesso:

\section{https://www.nucleodoconhecimento.com.br/saude/genetica-medica,}

DOI: 10.32749/nucleodoconhecimento.com.br/saude/genetica-medica

\section{RESUMO}

A disciplina Genética possui papel fundamental na formação acadêmica e profissional dos discentes de Medicina. Dessa maneira, é necessário que a sua percepção seja regular ou boa durante os ciclos básico, clínico e internato do curso, para que se possa nortear uma boa conduta profissional e condicionar impulsos à saúde do paciente. O estudo possui como objetivo principal avaliar a percepção dos discentes do curso de Medicina sobre Genética Médica durante o curso e vida

\footnotetext{
${ }^{1}$ Acadêmico de Medicina do Centro Universitário do Estado do Pará - CESUPA.

${ }^{2}$ Acadêmica de Medicina do Centro Universitário do Estado do Pará - CESUPA.

${ }^{3}$ Teóloga, Doutora em Psicanálise Clínica. Atua há 15 anos com Metodologia Científica ( Método de Pesquisa) na Orientação de Produção Científica de Mestrandos e Doutorandos. Especialista em Pesquisas de Mercado e Pesquisas voltadas a área da Saúde.

${ }^{4}$ Doutora em Genética Médica. Docente e Pesquisadora do Centro Universitário do Estado do Pará (CESUPA).

${ }^{5}$ Doutor em Medicina/Doenças Tropicais. Docente e Pesquisador na Universidade Federal do Pará - UFPA. Pesquisador na Universidade Federal do Pará/UFPA.
}

RC: 79752

Disponível em: https://www.nucleodoconhecimento.com.br/saude/genetica-medica 
profissional, em um Centro Universitário de Belém, Pará, Amazônia. Trata-se de uma pesquisa de abordagem quantitativa, onde foi aplicado um questionário elaborado pelos pesquisadores com perguntas abertas e fechadas. Os dados coletados foram analisados e tabulados em gráficos e tabelas desenvolvidos através do Microsoft Excel 2017. Foram entrevistados 120 discentes do $1^{\circ}$ ao $12^{\circ}$ semestre do curso, onde $90 \%$ afirmaram ter dificuldades no curso da disciplina, 62,5\% tiveram seus conhecimentos ampliados após a realização da mesma, porém, 75\% consideraram que a disciplina foi insuficiente para abordar toda extensão do assunto. Sugere-se, então, que os discentes possam ter um maior contato com o tema, seja na forma de cursos ou de estágios extracurriculares.

Palavras-chave: Educação superior, genética, Educação médica.

\section{INTRODUÇÃO}

Desde 1932, a importância do ensino de Genética nos cursos de Medicina é discutida (MILLER, 2002). Em 1960, o Jackson Laboratory, situado em Bar Harbor nos Estados Unidos, promoveu um curso com objetivo de apresentar produções acadêmicas atualizadas, como forma de qualificação para docentes (LINDEE, 20020).

Em Genebra, no ano de 1961, a Organização Mundial da Saúde realizou uma reunião com especialistas globais para discutir a procedência de adequações no ensino da Genética nos cursos de Medicina dos diversos países. O Brasil foi representado pelo, então docente da Universidade de São Paulo, Oswaldo FrotaPessoa, idealizador de várias mudanças curriculares do curso no Brasil (FROTAPESSOA, 1996).

Os conhecimentos da Genética crescem nos variados cursos superiores da área de saúde, já que esta passa a ser reconhecida como formadora de uma prática clínica e laboratorial com importância para a educação e prática da saúde, no que tange, principalmente, diagnósticos precoces (NUSSBAUM et al., 2016).

RC: 79752

Disponível em: https://www.nucleodoconhecimento.com.br/saude/genetica-medica 
No entanto, nota-se, por exemplo, que nas escolas brasileiras de Ensino Médio, conteúdos relacionados à Genética são abordados de forma superficial, traduzindose pela dificuldade dos docentes em demonstrá-los, por serem considerados abstratos e de difícil compreensão (LORETO; SEPEL, 2006). Dessa forma, ao cursar a disciplina no nível superior, os discentes apresentam dificuldades em adequar os temas para a prática clínica, o que justifica a disciplina Genética com o maior índice de reprovação (FRANCISCO, 2005).

As Instituições de Ensino Superior (IES) possuem função determinante no desenvolvimento profissional futuro pelo seu papel único na definição da ética de desenvolvimento nacional e por ser um local de crítica e transformação social (GARCIA; BARROS, 2008). O docente, como representante das IES, e, ainda, difusor de conhecimento produz, então, efeitos com suas práticas na formação dos novos profissionais tanto na área do saber, quanto no pessoal (KOIFMAN, 2011). Dessa maneira, esclarece-se a avaliação dos discentes sobre a importância da Genética durante o curso e a vida profissional para que se possa aumentar os conhecimentos promovidos pelas IES aos acadêmicos.

Considerando a importância da Genética para a vida acadêmica e profissional, fazse necessário a coleta de informações com base no questionário proposto pelos pesquisadores sobre a avaliação da percepção dos discentes sobre a Genética, para que possam ser identificadas as etapas durante o curso de Medicina em que a Genética Médica é mais valorizada e analisar o conhecimento dos discentes em relação às consequências da não valorização da disciplina. Diante disso, mostra-se relevante a realização desse estudo aplicado, visto que podem ser impulsionadas melhorias na Educação em Genética Médica.

\section{MATERIAL E MÉTODO}

Trata-se de um estudo do tipo quantitativo, realizado na cidade de Belém, Estado do Pará, que avaliou a percepção dos discentes de Medicina de um Centro Universitário sobre a importância da Genética durante o curso e a vida profissional.

RC: 79752

Disponível em: https://www.nucleodoconhecimento.com.br/saude/genetica-medica 
Este projeto foi submetido e aprovado pelo Comitê de Ética em Pesquisa com Seres Humanos conforme parecer nํㅜㄹ.998.139.

Todos os participantes da pesquisa (mantido seu anonimato) assinaram o Termo de Consentimento Livre e Esclarecido. Bem como o protocolo deste estudo seguiu rigorosamente as normas da Resolução n466/12 do Conselho Nacional de Saúde do Brasil (BRASIL, 2012), que estabelece normas para pesquisas envolvendo seres humanos.

Foram incluídos na pesquisa os discentes entre o $1^{\circ}$ e $12^{\circ}$ períodos do curso e que aceitaram responder ao questionário solicitado. Foram excluídos da pesquisa os discentes que estavam em férias ou que se recusaram a responder ao questionário. O questionário foi elaborado pelos próprios pesquisadores, composto por perguntas fechadas, dividido em indagações referentes às questões sociodemográficas e acadêmicas, considerando-se aspectos como sexo, idade, semestre atual do curso, período que realizou a disciplina Genética, conhecimento prévio suficiente para realização da disciplina e dificuldades durante sua efetivação.

Os dados coletados foram analisados e tabulados em gráficos e tabelas desenvolvidos através do Microsoft Excel 2017.

\section{RESULTADOS}

Foram analisados 120 questionários, sendo 10 participantes de cada semestre letivo do curso de Medicina ( $1^{\circ}$ ao $\left.12^{\circ}\right)$. Do total, 47 participantes eram do sexo masculino e 73, do feminino.

A análise dos dados possibilitou afirmar que $60 \%$ dos discentes abordados tem conhecimento prévio abrangente do Ensino Médio, que puderam utilizar durante o módulo de Genética, que no Centro Universitário onde o estudo foi realizado, é previsto em grade curricular durante o primeiro semestre do curso (Figura 1).

RC: 79752

Disponível em: https://www.nucleodoconhecimento.com.br/saude/genetica-medica 
Figura 1: Conhecimento prévio abrangente do Ensino Médio.

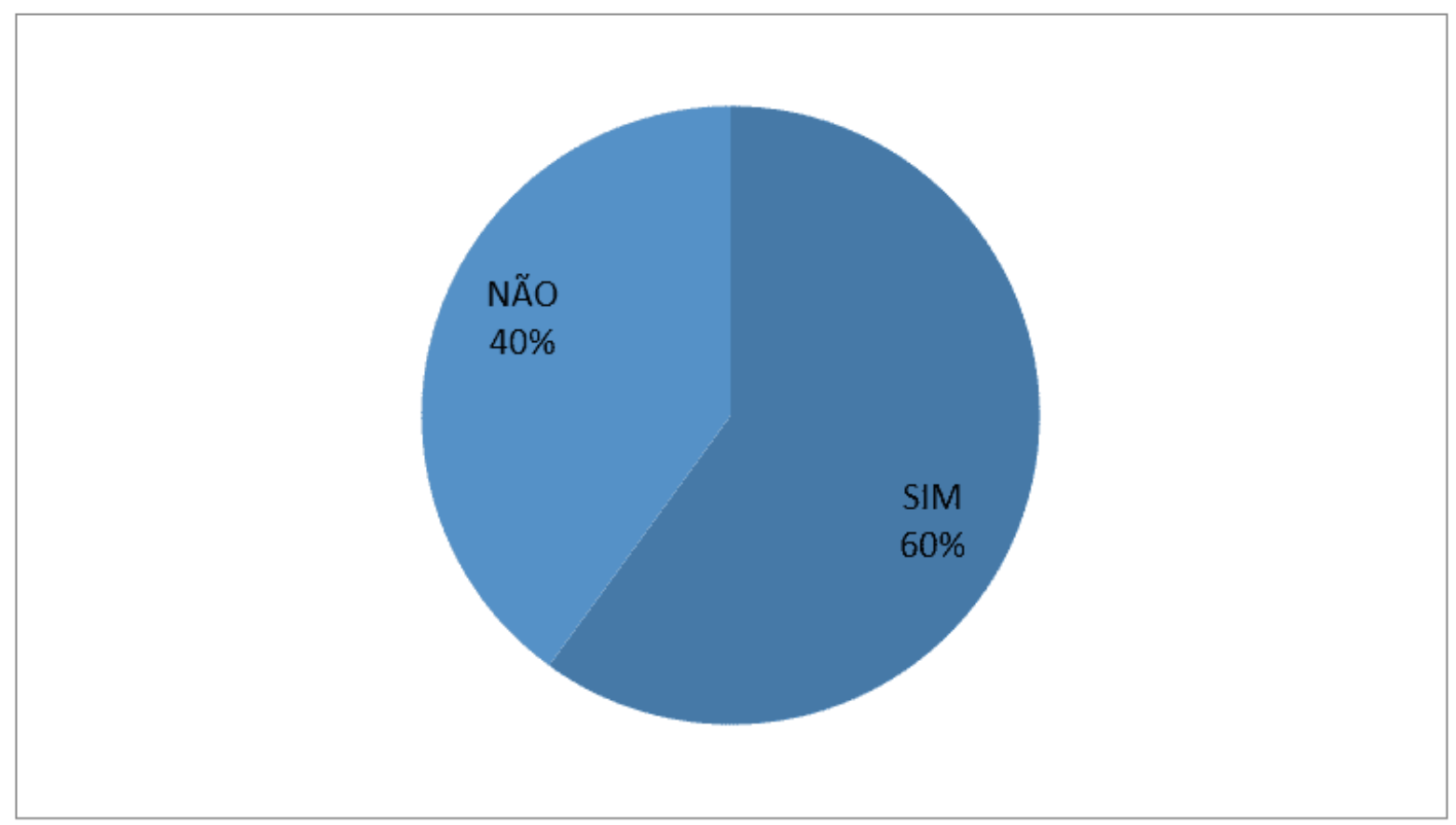

Fonte: Dados da pesquisa.

Dos entrevistados, $90 \%$ relataram ter tido dificuldades durante a realização da disciplina (Figura 2), destacando-se o primeiro semestre do curso com mais dificuldades (Figura 3).

RC: 79752

Disponível em: https://www.nucleodoconhecimento.com.br/saude/genetica-medica 
Figura 2: Dificuldades durante a disciplina.

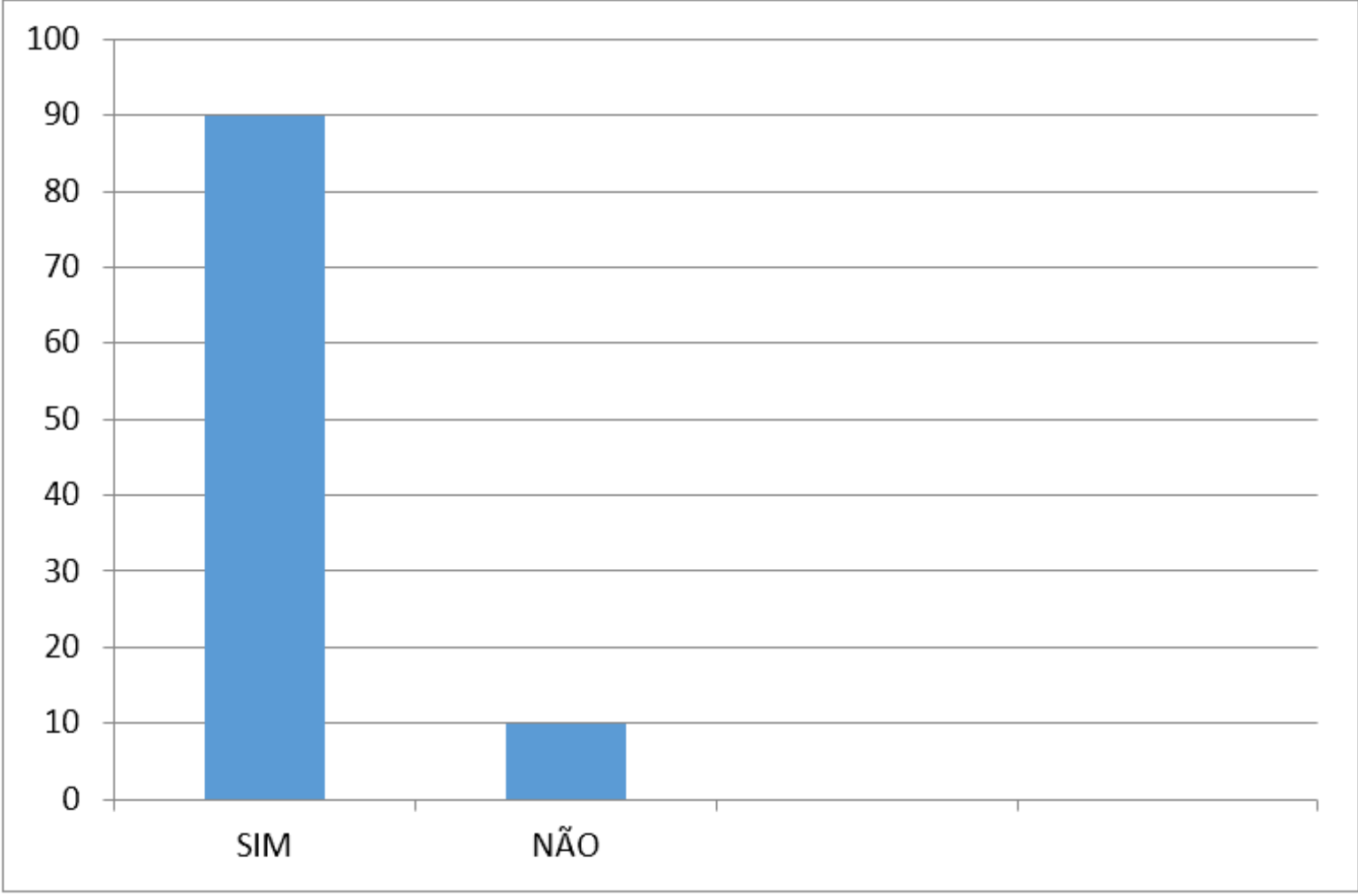

Fonte: Dados da pesquisa.

RC: 79752

Disponível em: https://www.nucleodoconhecimento.com.br/saude/genetica-medica 
Figura 3: Dificuldades durante a disciplina por semestre letivo.

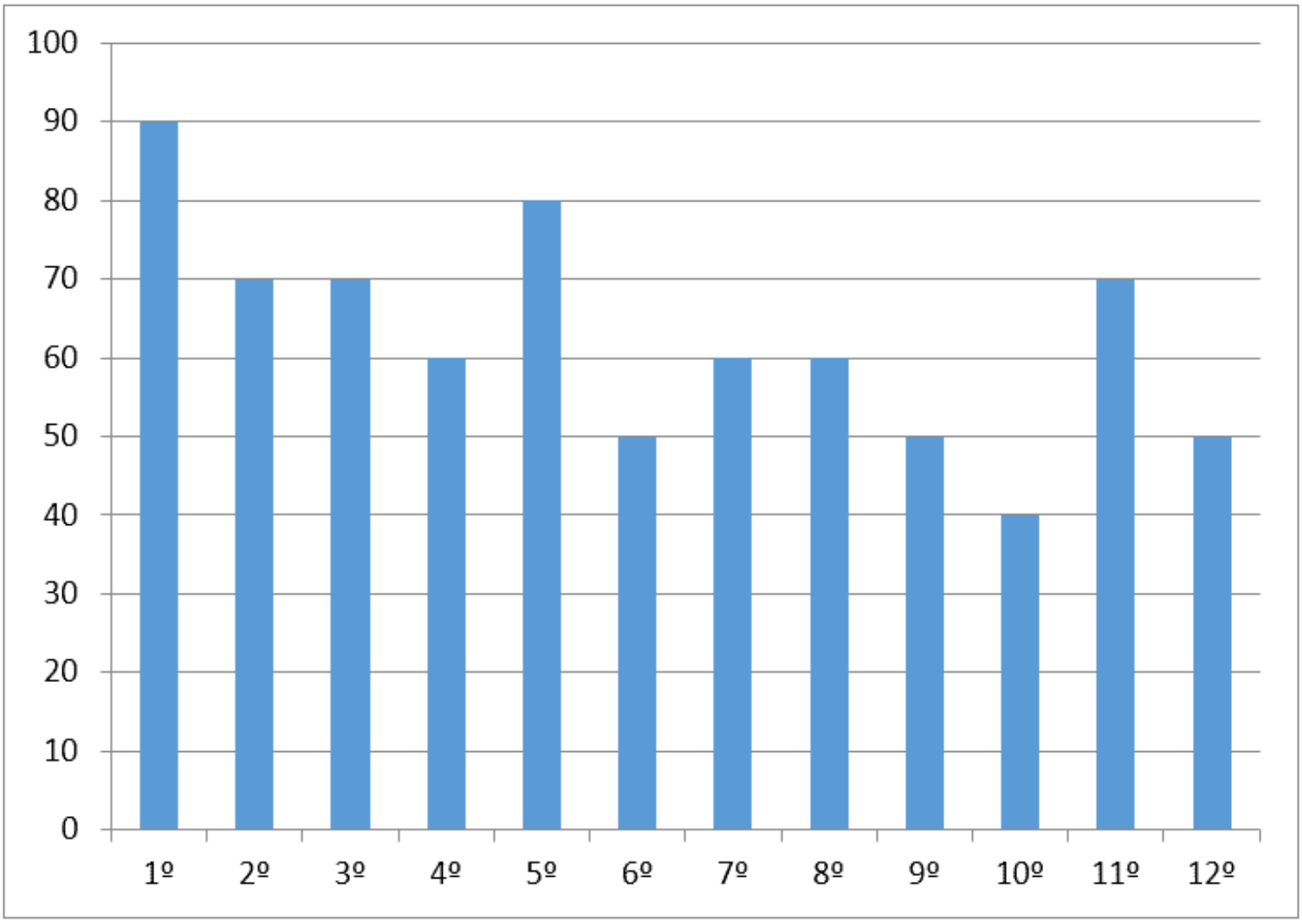

Fonte: Dados da pesquisa.

Dentre os discentes interrogados, $62,5 \%$ afirmaram que os conhecimentos sobre Genética foram ampliados a partir da realização do módulo (Figura 4). Entretanto, $75 \%$ informaram que apenas a disciplina não foi suficiente para demonstrar toda abrangência do tema (Figura 5). A totalidade dos discentes entrevistados do $2^{\circ}, 3^{\circ}$, $6^{\circ}$, $9^{\circ}$ e $12^{\circ}$ semestres letivos, consideram que apenas o módulo não é capaz de abordar toda extensão da Genética (Figura 6).

RC: 79752

Disponível em: https://www.nucleodoconhecimento.com.br/saude/genetica-medica 
Figura 4: Conhecimentos ampliados após a realização da disciplina.

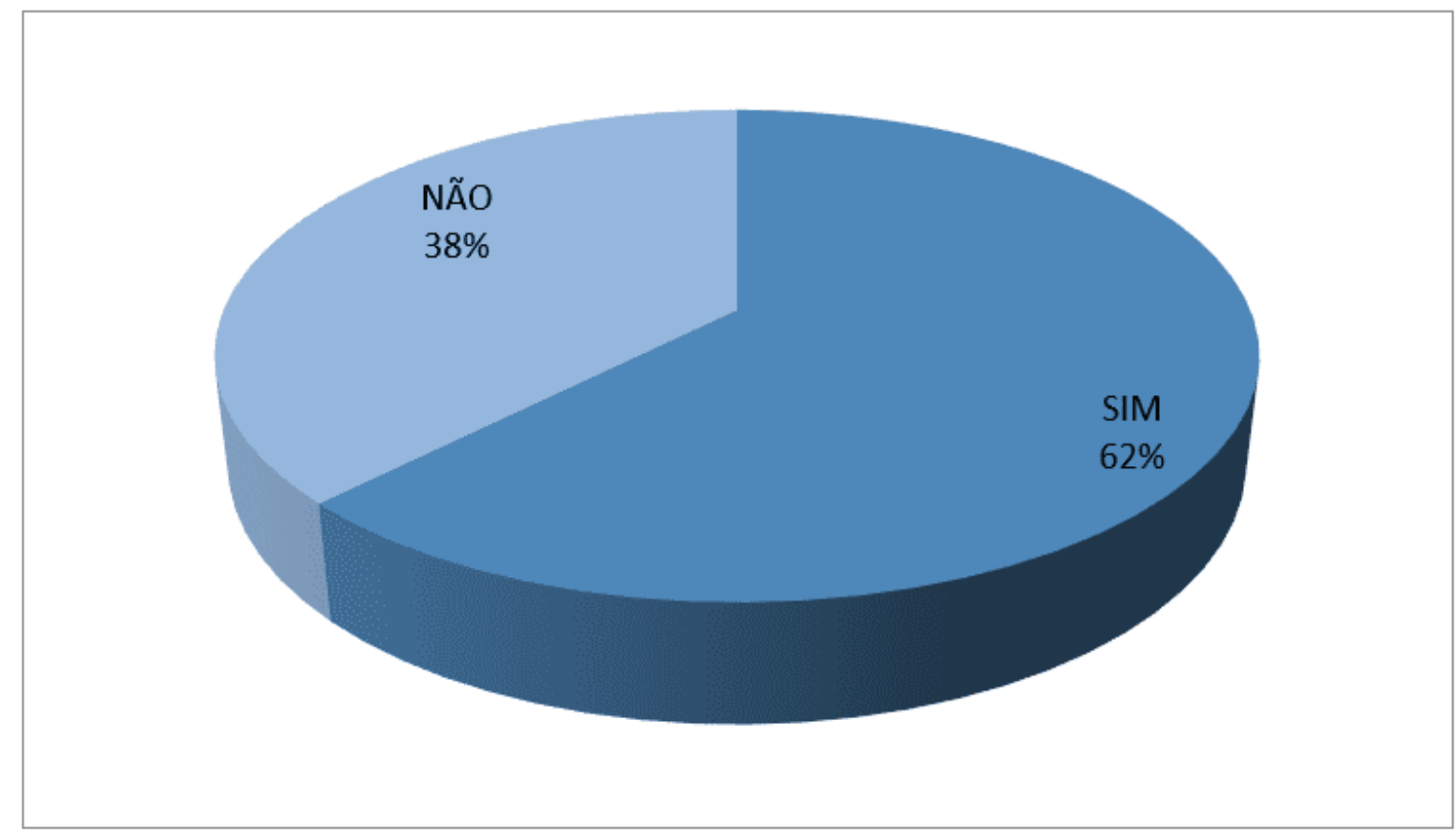

Fonte: Dados da pesquisa.

RC: 79752

Disponível em: https://www.nucleodoconhecimento.com.br/saude/genetica-medica 
Figura 5: Disciplina demonstrou a abrangência do tema

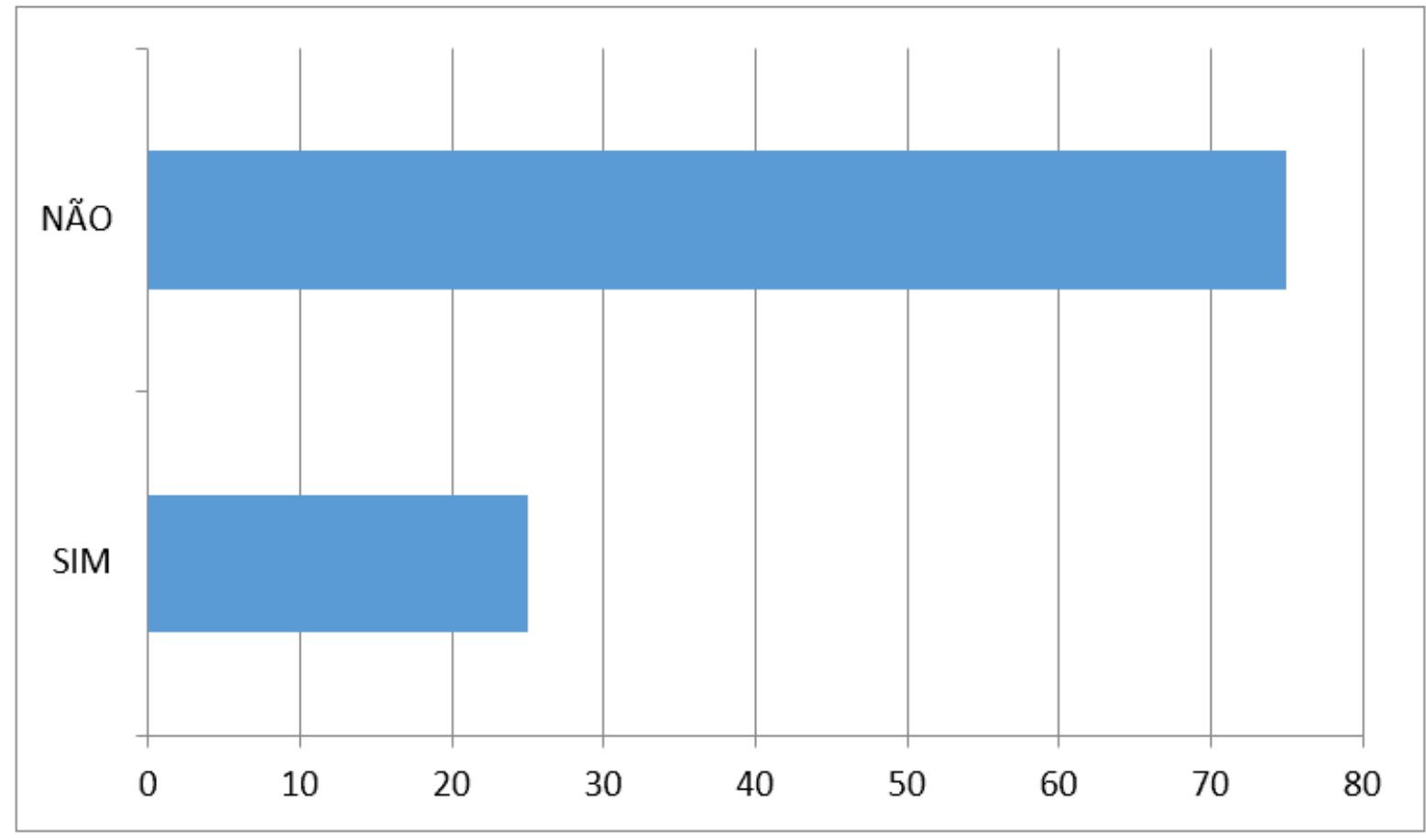

Fonte: Dados da pesquisa.

RC: 79752

Disponível em: https://www.nucleodoconhecimento.com.br/saude/genetica-medica 
Figura 6: Não abrangência do tema por semestre letivo.

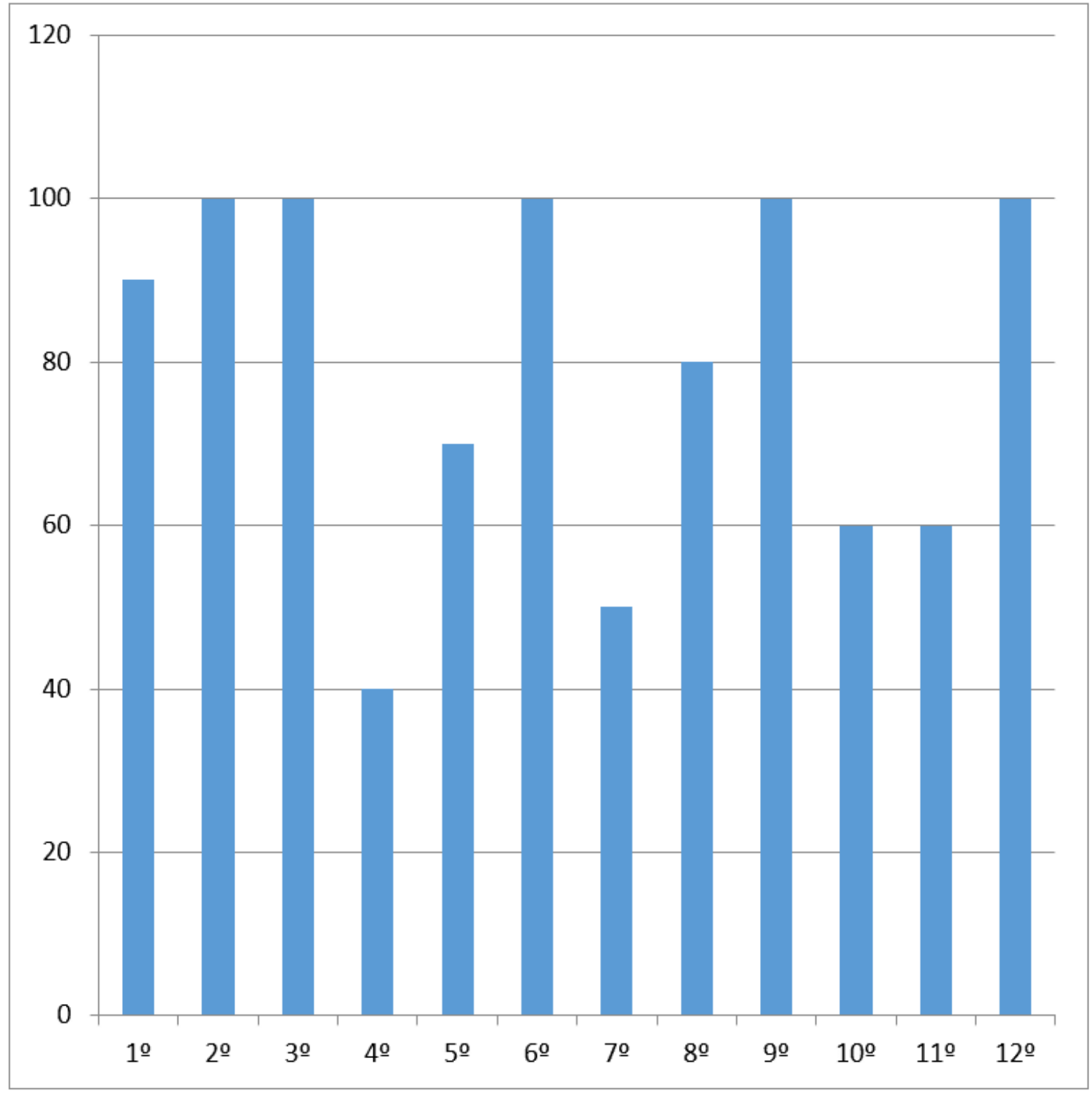

Fonte: Dados da pesquisa.

A existência do Ambulatório de Genética Médica no Centro de Especialidades Médicas do CESUPA (CEMEC) foi, totalmente, reconhecida pelos discentes do $5^{\circ} \mathrm{e}$ $8^{\circ}$ semestres letivos do curso. Em contraste, os discentes do $2^{\circ}$ e $9^{\circ}$ períodos, praticamente não o reconhecem (Figura 7). Dessa forma, do total dos participantes, apenas $35,83 \%$ participavam ou haviam participado de atividades no Ambulatório de

RC: 79752

Disponível em: https://www.nucleodoconhecimento.com.br/saude/genetica-medica 
Genética Médica, destacando-se o $5^{\circ}$ e $6^{\circ}$ semestres letivos (Figura 8). Quanto ao contato com a Genética Médica fora da IES, apenas $45 \%$ dos participantes haviam tido algum (Figura 9); além disso, 70\% dos entrevistados não tinham conhecimento do Grupo de Genética Médica da IES (Figura 10) e 20\% não sabiam da existência da residência em Genética Médica (Figura 11).

Figura 7: Conhecimento sobre o Ambulatório de Genética Médica do CEMEC

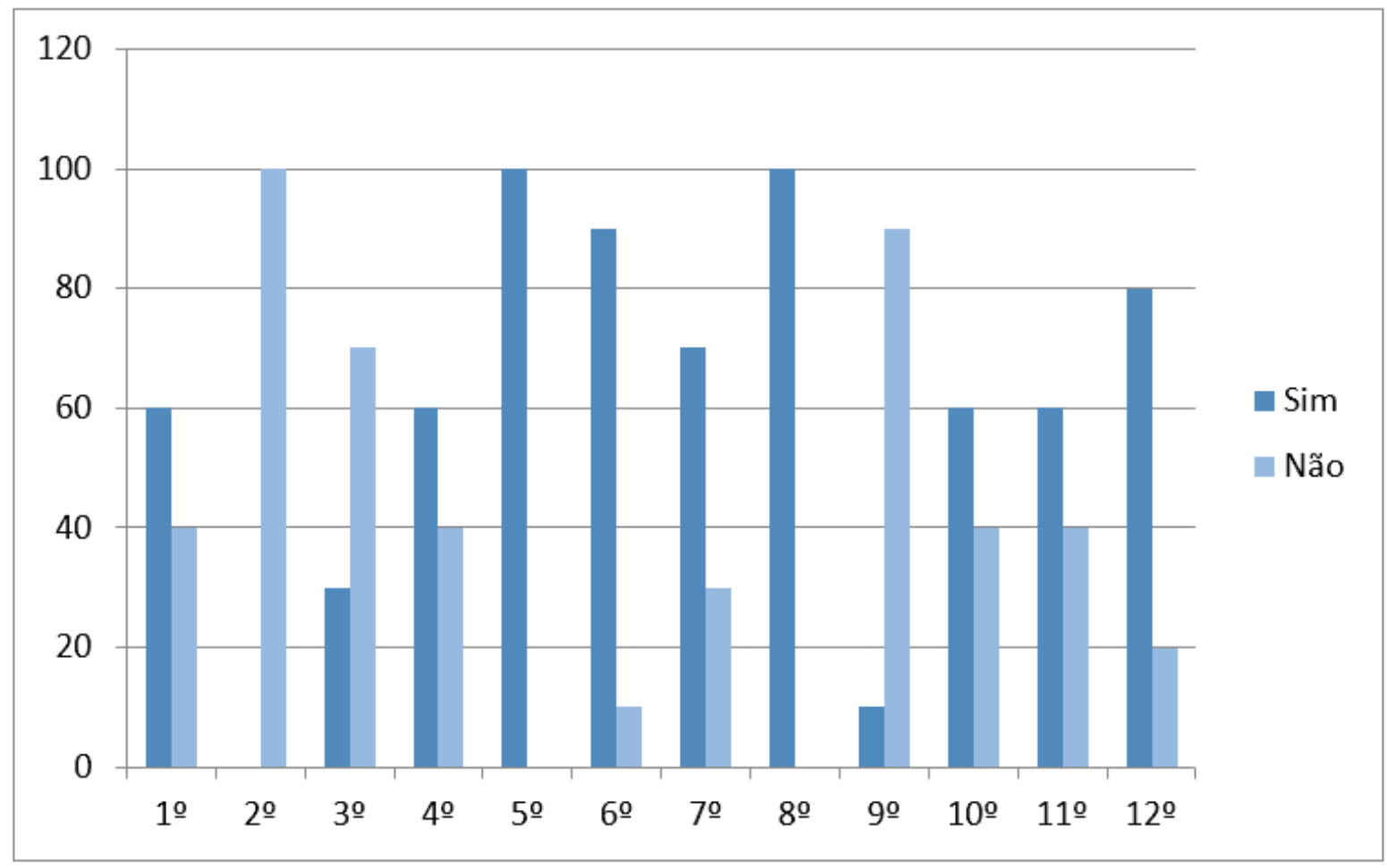

Fonte: Dados da pesquisa.

RC: 79752

Disponível em: https://www.nucleodoconhecimento.com.br/saude/genetica-medica 
Figura 8: Participação no Ambulatório de Genética Médica do CEMEC.

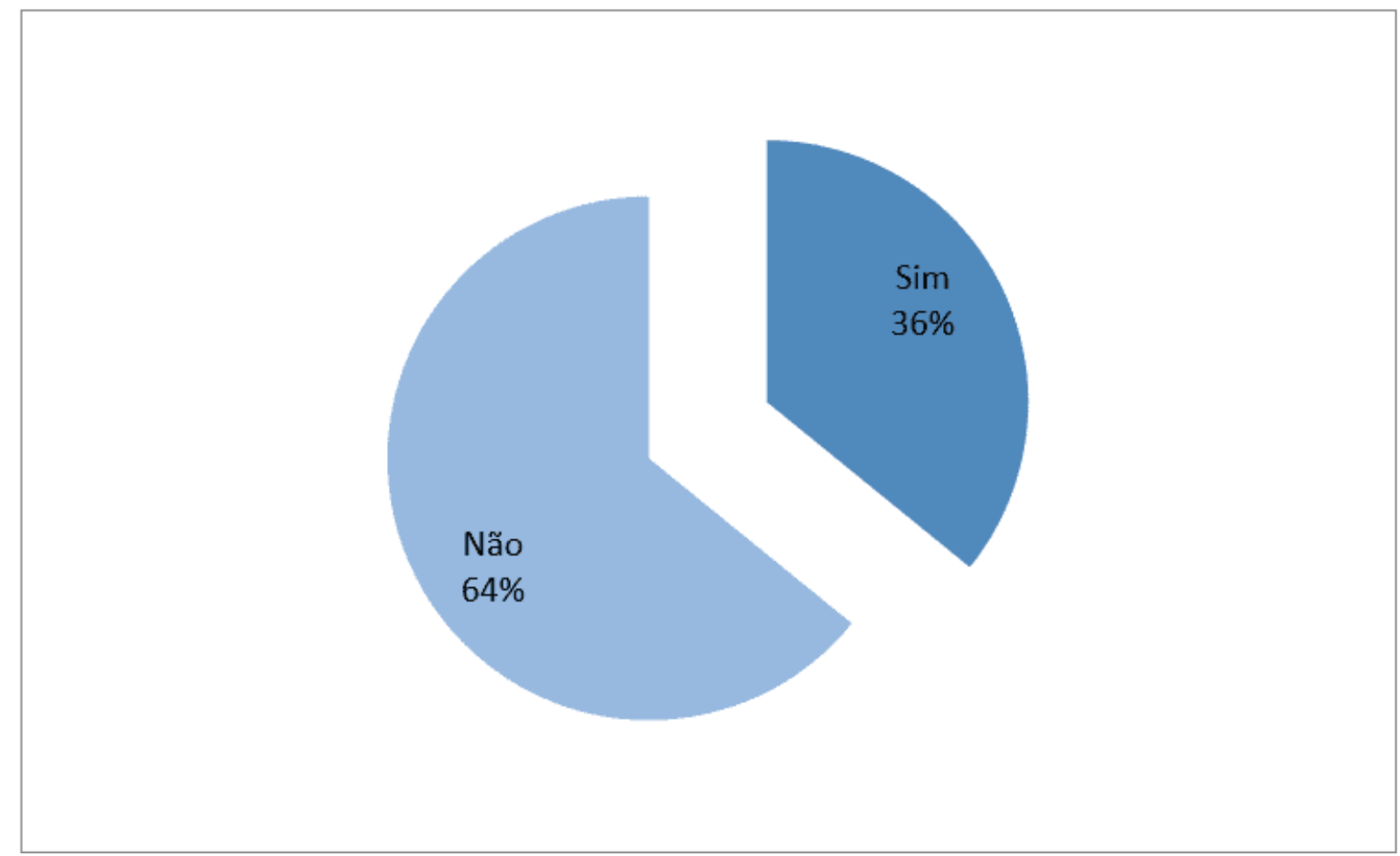

Fonte: Dados da pesquisa.

RC: 79752

Disponível em: https://www.nucleodoconhecimento.com.br/saude/genetica-medica 
Figura 9: Contato com a Genética Médica fora da IES.

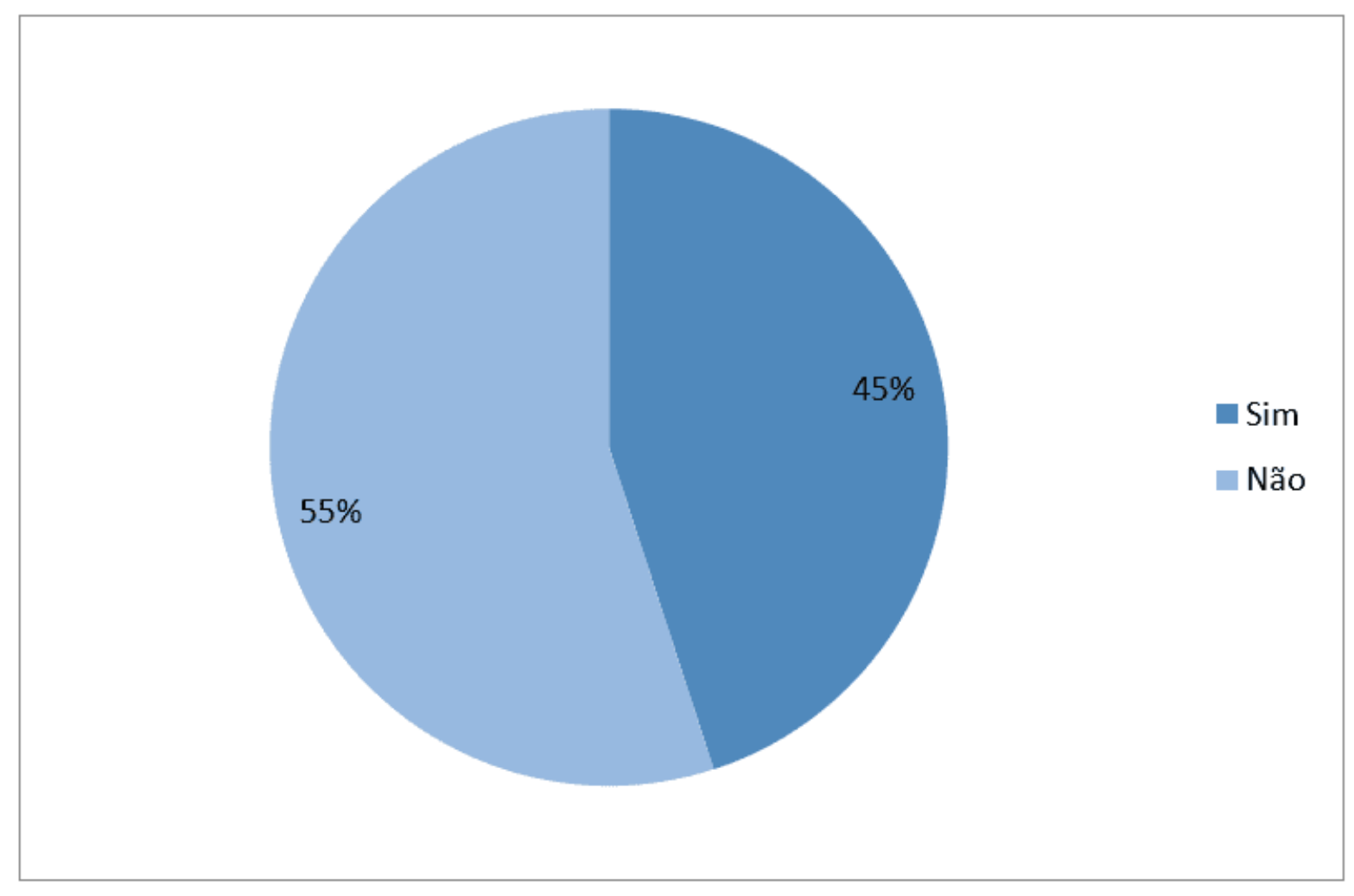

Fonte: Dados da pesquisa.

RC: 79752

Disponível em: https://www.nucleodoconhecimento.com.br/saude/genetica-medica 
Figura 10: Conhecimento do Grupo de Pesquisa de Genética Médica da IES.

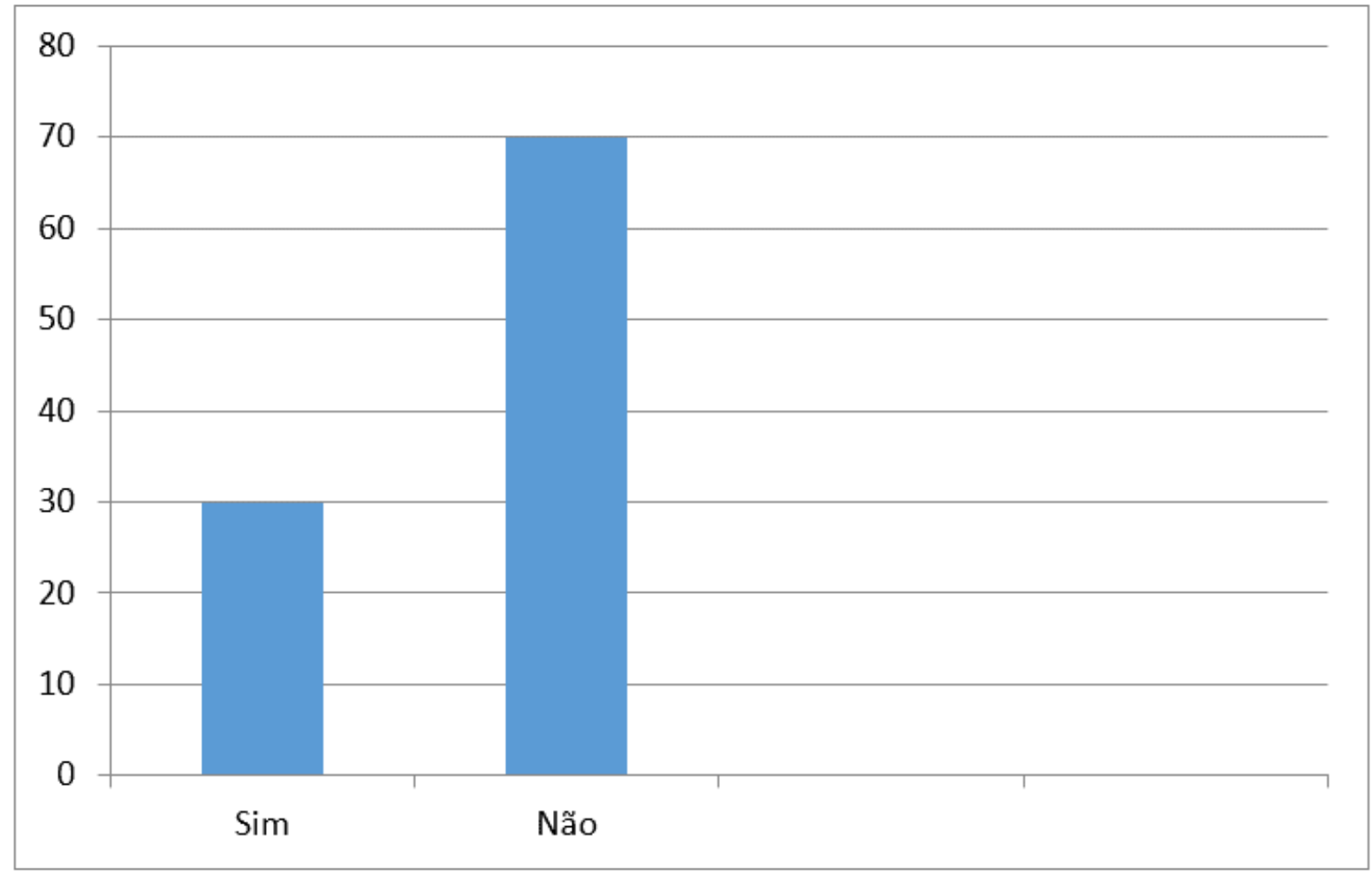

Fonte: Dados da pesquisa.

RC: 79752

Disponível em: https://www.nucleodoconhecimento.com.br/saude/genetica-medica 
Figura 11: Conhecimento da existência da Residência Médica em Genética Médica em \%.

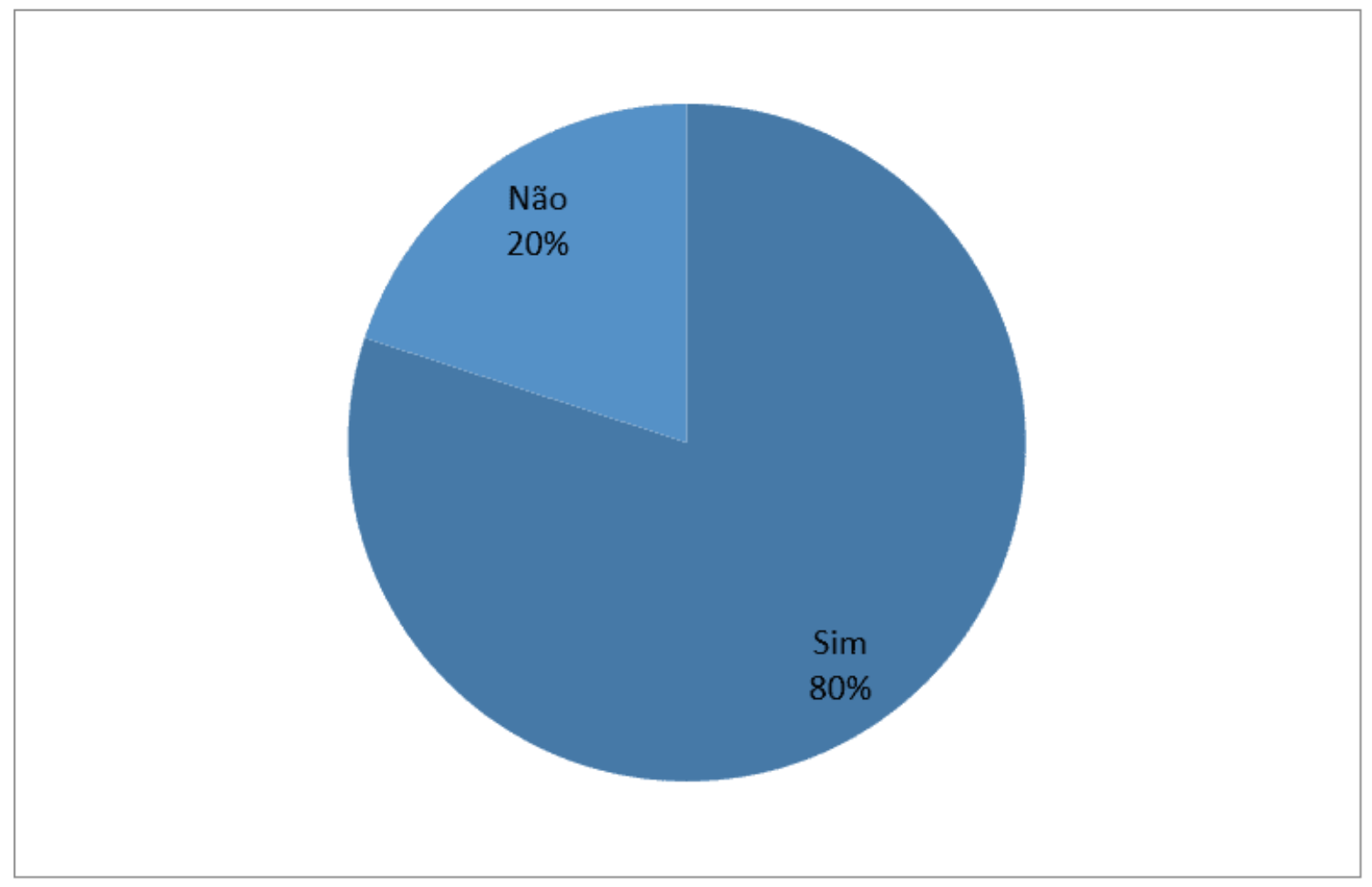

Fonte: Dados da pesquisa.

Os discentes do $2^{\circ}$ e $9^{\circ}$ semestres do curso foram os que mais consideraram que a disciplina não é valorizada na IES, com 100 e 80\%, respectivamente. Enquanto 70\% dos entrevistados do $3^{\circ}$ e $5^{\circ}$ semestres consideram que a disciplina é valorizada na IES (Figura 12).

RC: 79752

Disponível em: https://www.nucleodoconhecimento.com.br/saude/genetica-medica 
Figura 12: Valorização da disciplina por semestre letivo

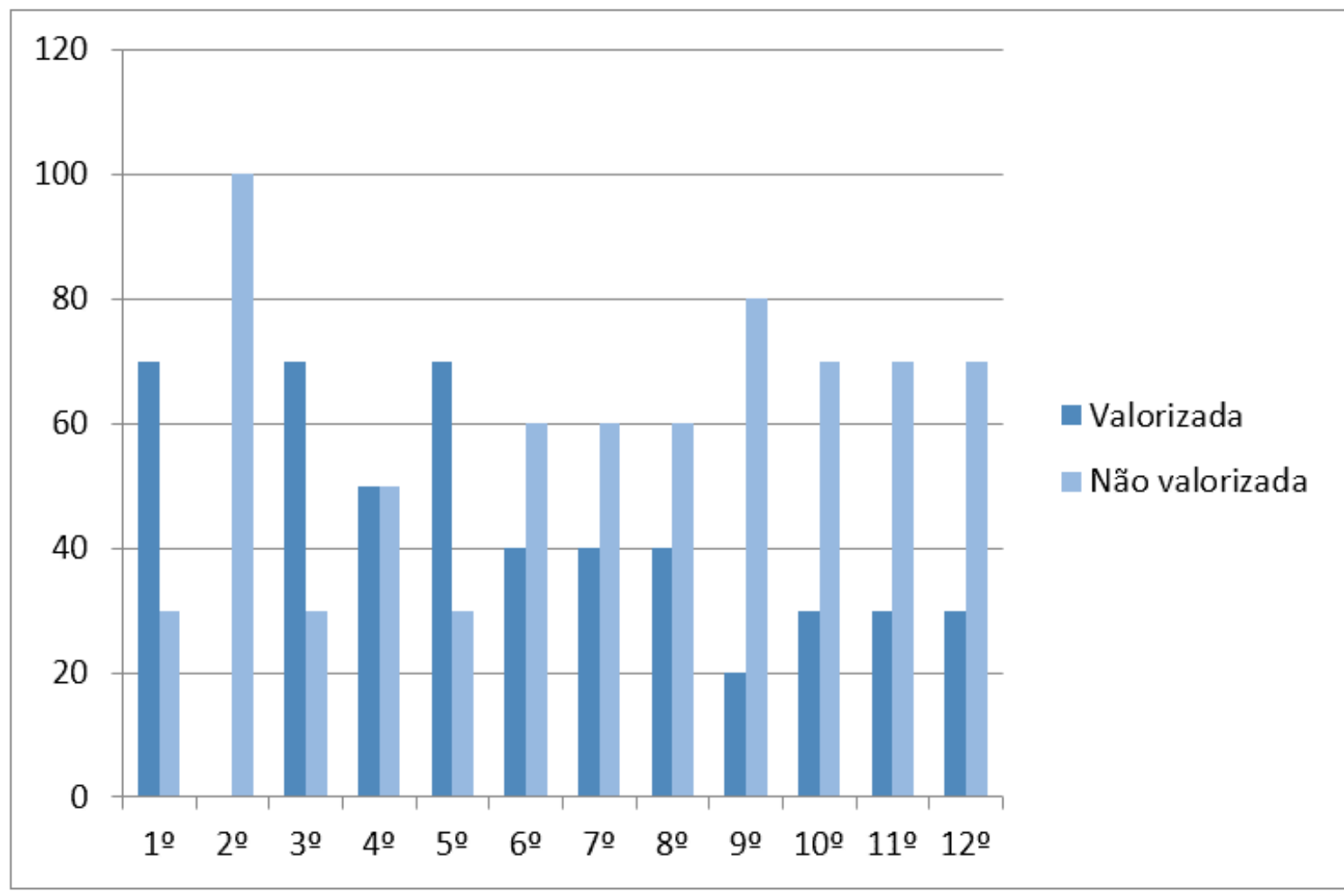

Fonte: Dados da pesquisa.

\section{DISCUSSÃO}

A análise dos dados revelou que a maioria dos entrevistados era do sexo feminino $(60,8 \%)$, seguindo a média nacional, onde as mulheres representam a maioria dos regularmente matriculados no Ensino Superior, desde a década passada (ARTES, 2016). A disciplina Genética é abordada de forma abstrata no Ensino Médio brasileiro e os livros didáticos utilizados no processo de ensino-aprendizagem estão desatualizados em temas considerados essenciais para ciência (MOURA; GONÇALVES; PERON, 2013). Entretanto, os dados analisados apresentaram $60 \%$ dos entrevistados afirmando ter conhecimento prévio abrangente sobre Genética, adquiridos no Ensino Médio. Esta discrepância pode ser justificada pelo fato do método aqui utilizado empregar um questionário com perguntas fechadas, com respostas do tipo "SIM" ou "NÃO", o que pode causar um viés.

RC: 79752

Disponível em: https://www.nucleodoconhecimento.com.br/saude/genetica-medica 
Como uma tentativa de minimizar as dificuldades na aprendizagem, evidencia-se a importância dos trabalhos lúdicos, incorporando novas abordagens da Genética e Biologia ao cotidiano, ampliando o conhecimento proposto e favorecendo o processo de assimilação, criatividade e desenvolvimento cognitivo ( MASCARENHAS et al., 2016). Quanto mais didáticas e aplicadas forem as estratégias utilizadas para facilitar a compreensão dos temas de Genética abordados no Ensino Médio, melhores serão os resultados apresentados pelos discentes no Ensino Superior. O que poderia, assim, minimizar as dificuldades durante a realização da disciplina nas escolas médicas.

As estratégias adotadas por autores sobre a utilização de flashcards didáticos, quis, mapa mental, aliados a outros recursos, comprova a facilitação e compreensão do exposto pelos alunos (BISSOLI, 2018) podendo ser alternativa para evitar dificuldades durante a realização da disciplina no Ensino Superior. Se aplicadas, espera-se, então, que o dado encontrado em que quase a totalidade dos discentes apresentou dificuldade na realização da disciplina na graduação, seja diminuído.

Dos entrevistados, $90 \%$ relataram ter dificuldades durante o curso da disciplina de Genética. Após o término, 62,5\% afirmaram que os conhecimentos sobre o tema foram ampliados. Entretanto, $75 \%$ consideraram que a disciplina foi insuficiente para abordar toda extensão do assunto. Ressalta-se, então, o fato da importância da autoaprendizagem contínua dentro do panorama da metodologia ativa, como formadora de um profissional médico crítico e reflexivo, como afirmam Prado e seus colaboradores (PRADO et al., 2012).

A Sociedade Brasileira de Genética Médica e Genômica (SBGM) definiu competências desajáveis em Genética para médicos do Brasil, dentre elas identificar indivíduos que apresentem ou possam desenvolver uma doença genética e saber quando referenciar tais pacientes (MELO et al., 2019). Assim, o Centro Universitário do Estado do Pará, onde a pesquisa foi desenvolvida, realizou uma mudança curricular no curso de Medicina em 2019, integralizando o Ambulatório de Genética Médica no $5^{\circ}$ semestre e a oferta de estágio extracurricular para disciplina, a partir

RC: 79752

Disponível em: https://www.nucleodoconhecimento.com.br/saude/genetica-medica 
do 6ํㅗㄹ semestre. Esta mudança pode justificar a falta de conhecimento dos discentes sobre a existência do serviço e também a baixa participação (35,83\%) nas atividades do mesmo, considerando que a pesquisa foi realizada no mesmo ano da mudança curricular.

A ideia de que as doenças genéticas são raras e que a Genética Médica é uma especialidade de custo elevado, praticável somente em hospitais de alta complexidade (MELO; GOMES, 2009) não favorece o interesse do acadêmico de Medicina. O que corrobora o resultado aqui obtido, onde $55 \%$ dos participantes afirmaram não ter tido qualquer contato com a disciplina além dos muros da IES. Aliado a isso, $70 \%$ dos interrogados não tinham conhecimento sobre o Grupo de Pesquisa em Genética Médica da IES, o que pode ser justificado por sua recente criação, falta de divulgação, desinteresse dos discentes ou, ainda, uma combinação destes fatores; o que só amplia esse panorama de não reconhecimento da Genética Médica. Contudo, de forma positiva, $80 \%$ dos discentes sabiam da existência da residência em Genética Médica.

A maioria dos participantes da pesquisa acredita que a IES não valoriza a Genética Médica, sendo aqueles matriculados nos $2^{\circ}$ e $9^{\circ}$ semestres os que mais têm essa percepção. O que pode ser justificado pelo fato de não visualizarem a aplicação dos conteúdos teóricos na prática clínica.

\section{CONCLUSÃO}

Após análise dos dados, foi possível perceber que os problemas no ensino da Genética perpassam desde a sua aplicação no Ensino Médio até sua execução no Ensino Superior. Identifica-se a valorização da Genética no curso de Medicina nos períodos em que a sua prática ambulatorial se torna obrigatória. Entretanto, muitos ainda não a valorizam, mas reconhecem sua importância ao classificar apenas um módulo como insuficiente para abranger os conhecimentos sobre o tema. Sugere-se, então, que o planejamento da disciplina seja revisto, para que os discentes possam

RC: 79752

Disponível em: https://www.nucleodoconhecimento.com.br/saude/genetica-medica 
ter um maior contato com o tema, seja na forma de cursos ou de estágios extracurriculares. Assim, é provável que a Genética Médica seja mais valorizada.

\section{REFERÊNCIAS}

ARTES, A. R. A. Mulheres no ensino superior brasileiro: espaço garantido e novos desafios. Ex aequo, n. 33, 2016, pp. 149-161.

BISSOLI, A. C. F. Produção de materiais didáticos para o ensino de genética na implementação da sala de aula invertida. Revista Ibero-Americana de Estudos em Educação. 2018; 13 n.2: 474-84.

FRANCISCO, G. C. B. Ensino de genética uma abordagem a partir dos estudos sociais de ciência e de tecnologia (ESCT). Blumenau: Universidade Regional de Blumenau; 2005.

FROTA-PESSOA, O. Living history-biography: a rambling rationalist. Am J Med Genet C Semin Med Genet. 1996; 63: 585-602.

GARCIA, A. L. O. E; BARROS, E. B. Qualidade de vida de professores do ensino superior na área da saúde: discurso e prática cotidiana. Cogitare Enferm. 2008; 13: $18-24$.

KOIFMAN, L. A função da universidade e a formação médica. Revista Brasileira de Educação Médica. 2011; 35: 145-6.

LINDEE, M. S. Genetic disease in the 1960s: a structural revolution. Am J Med Genet C Semin Med Genet. 2002; 115: 75-82.

LORETO, E. L. S.; SEPEL, L. M. N. Formação continuada de professores de biologia do ensino médio atualização em genética e biologia molecular: programa de incentivo à formação continuada de professores do ensino

RC: 79752

Disponível em: https://www.nucleodoconhecimento.com.br/saude/genetica-medica 
médio. Santa Maria: Universidade Federal de Santa Maria: Departamento de Biologia. 2006.

MASCARENHAS, M. J. O.; MARTINS, P. R. P; FRAGA, E. C.; BARROS, M. C. Estratégias metodológicas para o ensino de genética em Escola pública. Pesquisa em Foco, São Luís, vol. 21, n. 2, p. 05-24. 2016. ISSN: 2176-0136.

MELO, D. G.; GOMES, T. L. C. S. Capacitação em Genética Médica para residentes em Medicina de Família e Comunidade: relato de experiência. Revista de APS, v. 12, n. 1, p. 83-87, jan./mar. 2009.

MELO, D. G.; SILVA, A. A.; EL HUSNY, A. S.; FERRAZ, V. E. F.. Perfil de Competência em Genética para Médicos do Brasil: uma Proposta da Sociedade Brasileira de Genética Médica e Genômica. Revista Brasileira de Educação Médica. 43 (1 Supl. 1): 451-461; 2019.

MILLER, F. The importance of Being Margial: Norma Ford Walker and a Canadian School of Medical Genetics. Am J Med Genet C Semin Med Genet. 2002:115: 0210.

MOURA, J.; GONÇALVES, N. M. N.; PERON, A. Biologia/Genética: O ensino de biologia, com enfoque a genética, das escolas públicas no Brasil-breve relato e reflexão. Semina: Ciências Biológicas e da Saúde. 2013; 34: 167-74.

NUSSBAUM, R. L.; MCINNES, R. R.; HUNTINGTON, F. W.; THOMPSON, M. W. Thompson \& Thompson. Genetics in Medicine. Philadelphia: Elsevier. 2016.

PRADO, M. L; VELHO, M. B.; ESPÍNDOLA, D. S.; SOBRINHO, S. H.; BACKES, V. M. S. Arco de Charles Maguerez: refletindo estratégias de metodologia ativa na formação de profissionais de saúde. Escola Anna Nery. (impr.) 2012 jan-mar; 16 (1): 172-177.

Enviado: Março, 2021.

RC: 79752

Disponível em: https://www.nucleodoconhecimento.com.br/saude/genetica-medica 
Aprovado: Março, 2021.

RC: 79752

Disponível em: https://www.nucleodoconhecimento.com.br/saude/genetica-medica 